\title{
Strain-Based Evaluation of a Steel Through-Girder Railroad Bridge
}

\author{
Andrew N. Daumueller and David V. Jáuregui \\ Department of Civil Engineering, New Mexico State University, Hernandez Hall Box 30001, Las Cruces, NM 88003, USA \\ Correspondence should be addressed to Andrew N. Daumueller, adaumuel@nmsu.edu
}

Received 2 December 2011; Revised 18 May 2012; Accepted 21 May 2012

Academic Editor: Husam Najm

Copyright ( 2012 A. N. Daumueller and D. V. Jáuregui. This is an open access article distributed under the Creative Commons Attribution License, which permits unrestricted use, distribution, and reproduction in any medium, provided the original work is properly cited.

\begin{abstract}
In the state of New Mexico (USA), passenger rail began in 2008 between Belen and Santa Fe on the Rail Runner, following the acquisition of about 100 miles of existing rail and related infrastructure. Many of the bridges on this route are over 100 years old and contain fatigue prone details. This study focuses on a steel through-girder bridge along this corridor. To accurately evaluate these structures for load carrying capacity and fatigue, an accurate analytical model is required. Accordingly, four models were developed to study the sensitivity of a bridge in New Mexico to floor-system connection fixity and the ballast. A diagnostic load test was also performed to evaluate the accuracy of the finite-element models at locations of maximum moments. Comparisons between the simulated and measured bridge response were made based on strain profiles, peak strains, and Palmgren-Miner's sums. It was found that the models including the ballast were most accurate. In most cases, the pinned ended models were closer to the measured strains. The floor beams and girders were relatively insensitive to the ballast and end conditions of the floor-system members, whereas the stringers were sensitive to the modeling of the ballast.
\end{abstract}

\section{Introduction}

In the state of New Mexico, the Rail Runner commuter rail service was established in 2008. The state purchased about 100 miles of rail between Belen and Lamy, NM, for this purpose, which transferred responsibility of all related infrastructure to the state. One major responsibility that the state acquired was the periodic inspection and load carrying capacity evaluation of each of the bridges. The goal of this study is to develop analytical models that accurately describe the behavior of a steel through-girder bridge along the route purchased by the state. It was found in the literature that the effects of the end fixity of the floor-system members [1] and the ballast, ties, and rails $[2,3]$ may be significant. This model will subsequently be used in a fatigue evaluation. This study will also add to the area of evaluating railroad bridges, particularly those under commuter traffic.

1.1. Fatigue. Fatigue is generally evaluated in one of two ways, fracture mechanics or SN methods. Fracture mechanics methods often involve the equation developed by Paris et al. [4], which relates the rate of crack growth (with respect to the number of stress cycles) to various constants that describe the material and the geometry/type of detail. When rearranged, the Paris equation can yield the number of stress cycles until failure at a given constant amplitude stress range magnitude. This approach is not commonly used for highway and railroad bridges in the U.S. since the corresponding bridge design specifications $[5,6]$ emphasize the SN method. This method requires curves that relate the stress range magnitude, $S$, to the number of constant amplitude fatigue cycles, $N$, that can be withstood by the detail before failure (i.e. SN curves). In the AASHTO [5] and AREMA [6] specifications, various curves are given that describe the fatigue limits for a range of common details. The $\mathrm{SN}$ curves provided in the specifications are based on fullsized fatigue tests using a uniform probability of failure.

One issue that must be addressed in using SN curves for bridges is that the curves are developed under constant amplitude stress ranges, whereas real bridge live loads are of variable amplitude since vehicles of varying weight traverse the structure. This issue is commonly addressed in one of 
two ways. The first is to determine an "equivalent" constant amplitude stress range, and the corresponding number of cycles. This is done by estimating the stress histories caused by historical truck or train traffic that has crossed the structure. Obtaining accurate stress histories is often one of the most difficult aspects of a fatigue evaluation since a representative structural model is required, along with reliable historical traffic data. Once the stress histories are obtained, further analysis is required to obtain the stress ranges which may be achieved by applying a rainflow algorithm. This analysis is simplified somewhat by the fact that the fatigue model used is typically a linear model, meaning that repeating vehicles only need to be evaluated once, and the result multiplied by the number of stress cycles caused by the vehicle based on the number of crossings. The effective stress range can then be determined as follows, using the root mean cube of stress ranges:

$$
S_{\mathrm{Re}}=\left(\sum_{i}\left(\frac{n_{i}}{N_{\text {total }}} S_{i}^{3}\right)\right)^{1 / 3},
$$

where $S_{\mathrm{Re}}$ is the effective stress range; $n_{i}$ is the number of stress cycles at the $i$ th stress range magnitude; $N_{\text {total }}$ is the total number of stress ranges considered; $S_{i}$ is the $i$ th stress range magnitude. The effective stress range with its corresponding $N\left(N_{\text {total }}\right.$ from (1) $)$ can then be plotted and the suitability for fatigue can be determined based on whether that point lies above or below the corresponding SN curve.

The other common method for performing a fatigue evaluation based on SN curves is based on the equation developed by Palmgren [7] and popularized by Miner [8], known as the Palmgren-Miner's rule. This is a linear cumulative fatigue estimate as given by the following equation:

$$
D=\sum_{i} \frac{n_{i}}{N_{i}}
$$

where $D$ is the Palmgren-Miner's sum; $n_{i}$ is the number of stress ranges at the $i$ th stress range magnitude; $N_{i}$ is the number of stress cycles that can be withstood by the detail at the ith stress range magnitude according to the corresponding SN curve. One advantage of this method is that the remaining life of the structure can be estimated. To do so, the Palmgren-Miner's sum to date is first determined and the effect of future traffic is then approximated by measuring the strains under live load for a representative period of time to create a "loading block." The same traffic pattern can then be assumed to repeat indefinitely or increase in volume and/or weight at some assumed rate (e.g., 5\% per year). If the traffic is assumed to remain the same, the Palmgren-Miner's sum of all traffic in the "loading block" can be determined, and the remaining life may be calculated as:

$$
T=\frac{D_{f}-D_{h}}{D_{\mathrm{LB}}},
$$

where $T$ is the time until fatigue failure; $D_{f}$ is the PalmgrenMiner's sum at failure; $D_{h}$ is the Palmgren-Miner's sum to date; $D_{\mathrm{LB}}$ is the Palmgren-Miner's sum accumulated under

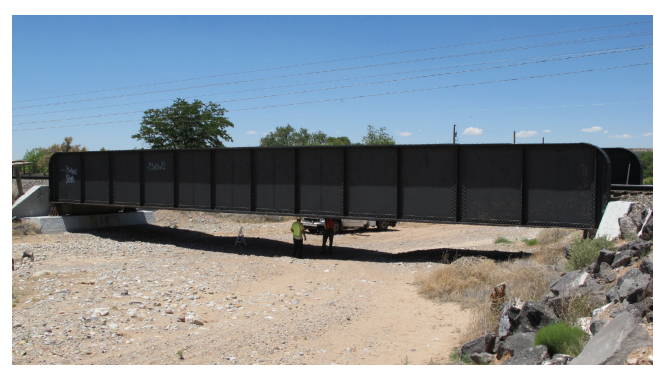

FIgURE 1: Photograph of Rail Bridge at MP 880.37 (Algodones, NM).

the "loading block." The Palmgren-Miner's sum at failure is theoretically 1.0; however, some studies have shown that a lower value is appropriate, particularly when the magnitude of the stress ranges increases over time [9].

1.2. Bridge Location and Description. The state of New Mexico's purchase of the railroad track between Belen and Lamy, NM, to carry the New Mexico Rail Runner required the state to inspect and evaluate all the bridges on the line in accordance with federal regulations [10]. Since many are steel structures over 100 years old, fatigue may be an issue due to the large number of trains that have crossed these structures. Another reason for concern is that the first fatigue provisions entered the AREMA specifications in 1910 after some of these structures were designed [6], including the bridge evaluated in this paper.

The bridge investigated herein is located at milepost (MP) 880.37 near Algodones, NM and carries the railway over an arroyo (see Figure 1). This structure is a ballastdeck, steel through-girder bridge built in 1898. Ballasted decks have a deck that supports crushed stone, which in turn supports the ties and rails on which the trains travel. Through-girder structures consist of two plate girders located on either side of the railway; floor beams are placed transversely and support smaller longitudinal members called stringers, which in turn carry the deck. Currently, this Bridge only carries Rail Runner and Amtrak trains, but historically freight trains and other passenger trains crossed this structure on a regular basis.

The ballast depth of Bridge 880.37 is approximately $25.4 \mathrm{~cm}$ from the top of the timber deck to the bottom of the ties based on measurements taken during the last inspection in March 2011. The treated timber ties are spaced $49.5 \mathrm{~cm}$ center-to-center and are $16.5 \mathrm{~cm}$ high, $21.6 \mathrm{~cm}$ wide, and $2.59 \mathrm{~m}$ long. The rails are spaced at $1.44 \mathrm{~m}$ from inside to inside (i.e., gauge distance) and weigh $67.5 \mathrm{~kg} / \mathrm{m}$.

The floor system of bridge 880.37 consists of two $26.67 \mathrm{~m}$ long riveted plate girders that are built up using a $2.53 \mathrm{~m} \times$ $0.953 \mathrm{~cm}$ web plate and two $15.2 \mathrm{~cm} \times 15.2 \mathrm{~cm} \times 2.22 \mathrm{~cm}$ angles for the top and bottom flanges. Cover plates that are $40.6 \mathrm{~cm} \times 1.59 \mathrm{~cm}$ are also used; at midspan, four cover plates are used on both the top and bottom flanges. The floor beams are also built-up steel members that consist of a $61.0 \mathrm{~cm} \times$ $1.43 \mathrm{~cm}$ web plate and $15.2 \mathrm{~cm} \times 15.2 \mathrm{~cm} \times 2.06 \mathrm{~cm}$ double angles. The stringers are rolled steel I 12X35 shapes that are 

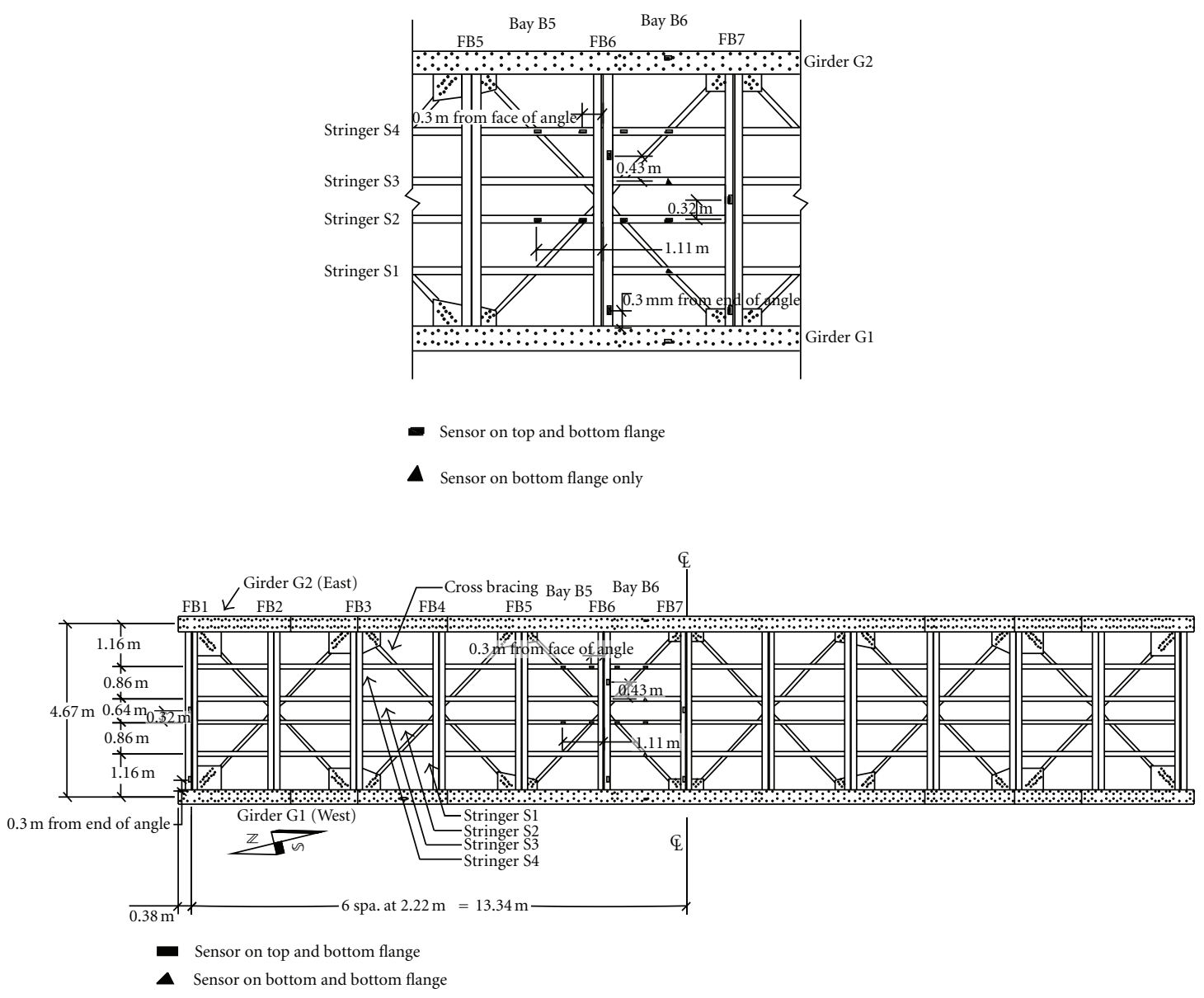

FIgURE 2: Framing plan and sensor locations for Bridge 880.37.

rivet connected to the floor beams using $15.2 \mathrm{~cm} \times 15.2 \mathrm{~cm} \times$ $1.27 \mathrm{~cm}$ double angles. The girders (labeled G1 and G2), floor beams (labeled FB1 through FB13), and stringers (labeled S1 through S4) are shown in Figure 2. All connections are made using rivets with a shank diameter of $2.22 \mathrm{~cm}$.

The deck between the floor beams consists of $14.0 \mathrm{~cm} \times$ $19.1 \mathrm{~cm} \times 4.27 \mathrm{~m}$ treated timbers placed perpendicular to the stringers and resting directly on the top flanges. Over the floor beams, $1.27 \mathrm{~cm}$ thick steel apron plates bridge over the top flange so that all loads are distributed to the floor beams via the stringers. Timber ballast curbs are placed along the edges of the deck to ensure that the ballast remains in place.

\section{Finite Element Models}

Four static linear elastic finite-element models were developed. Models 1 and 2 only included the primary structural members (i.e., girders, floor beams, and stringers). Furthermore, model 1 used pinned connections between floor system elements, while model 2 used fixed connections. Models 3 and 4 were then created to more accurately model the live load distribution by adding the ballast and track structure to models 1 and 2.
2.1. Basic Models. In the basic models (models 1 and 2), the primary structural members of the floor system were modeled with frame elements. All of the frame elements were placed in the same vertical plane to simplify the floor system connections. Nodes were placed at locations of connectivity and approximately $0.152 \mathrm{~m}$ spacing for the floor beams and girders. For the stringers, nodes were spaced at $0.305 \mathrm{~m}$ intervals and at the connection locations. Moment influence lines were obtained using SAP2000 [11] by using a series of load cases, each with a unit load evenly distributed to the four stringers and representing a $0.305 \mathrm{~m}$ movement of the load.

Section properties were calculated for the builtup structural members. Since the girders and floor beams were riveted, the holes needed to be considered. Rivet holes in tension areas were deducted as per AREMA [6], whereas rivets in compression areas were assumed effective. As a result, the gross cross-sectional properties were used to calculate compressive stresses from simulated moments, and the net cross-sectional properties were used to calculate tensile stresses. Table 1 shows the net cross-sectional properties for girders and floor beams, and the gross properties for the stringers used in the basic models.

The moment influence lines for models 1 and 2 at select locations of the floor system members are shown in Figures 
TABLE 1: Section properties of the floor system members.

\begin{tabular}{|c|c|c|c|c|c|c|c|c|}
\hline & Area & Torsional constant & $I_{x}$ & $I_{y}$ & Major axis shear area & Minor axis shear area & $S_{x}$ & $S_{y}$ \\
\hline & $\mathrm{cm}^{2}$ & $\mathrm{~cm}^{4}$ & $\mathrm{~cm}^{4}\left(* 10^{3}\right)$ & $\mathrm{cm}^{4}$ & $\mathrm{~cm}^{2}$ & $\mathrm{~cm}^{2}$ & $\mathrm{~cm}^{3}\left(* 10^{3}\right)$ & $\mathrm{cm}^{3}$ \\
\hline Girder $\mathrm{X}^{+}$ & 490.8 & 196.2 & 5059 & 540.7 & 241.4 & 174.2 & 3837 & 1108 \\
\hline Girder X2 ${ }^{+}$ & 513.7 & 238.7 & 5384 & 29611 & 241.4 & 200.0 & 3924 & 1457 \\
\hline Girder X3 ${ }^{+}$ & 560.0 & 292.9 & 6215 & 29611 & 241.4 & 264.5 & 4882 & 1457 \\
\hline Girder X $4^{+}$ & 674.2 & 1051 & 8122 & 47371 & 241.4 & 393.5 & 6302 & 2331 \\
\hline Girder X5 ${ }^{+}$ & 787.7 & 3111 & 10076 & 65128 & 241.4 & 522.6 & 7724 & 3205 \\
\hline Girder X6 $6^{+}$ & 901.9 & 7122 & 12078 & 82888 & 241.4 & 651.6 & 9148 & 4079 \\
\hline Floor beam & 294.7 & 148.3 & 170.4 & 5927 & 86.64 & 125.8 & 5.590 & 291.7 \\
\hline Stringer & 65.81 & 21.13 & 9.448 & 416.2 & 32.93 & 32.88 & 0.6194 & 20.48 \\
\hline
\end{tabular}

${ }^{+} \mathrm{X} 1$ through X6 denotes the different girder cross-sections based on the number of cover plates.

TABLE 2: Section properties of rails and ties.

\begin{tabular}{|c|c|c|c|c|c|c|c|c|}
\hline & Area & Torsional constant & $I_{x}$ & $I_{y}$ & Major axis shear area & Minor axis shear area & $S_{x}$ & $S_{y}$ \\
\hline & $\mathrm{cm}^{2}$ & $\mathrm{~cm}^{4}$ & $\mathrm{~cm}^{4}$ & $\mathrm{~cm}^{4}$ & $\mathrm{~cm}^{2}$ & $\mathrm{~cm}^{2}$ & $\mathrm{~cm}^{3}$ & $\mathrm{~cm}^{3}$ \\
\hline Rail & 86.00 & 259.7 & 3921 & 601.0 & 23.47 & 31.09 & 462.1 & 31.05 \\
\hline Ties & 356.5 & 16986 & 8097 & 13846 & 356.5 & 356.5 & 980.8 & 505.0 \\
\hline
\end{tabular}

3 through 5. Comparing moment influence lines for models 1 and 2 shows the sensitivity of the bridge response to the end fixity of the floor system members. It is clear that there was virtually no effect on the girders, and only a small effect on the stringers. The fixity of the floor system connections did not affect the girders because the end conditions of the girders were not changed and therefore acted as a simply supported beam in all cases. The end fixity had the greatest effect on the floor beams, particularly floor beam FB1, which was likely due to bearing restraint. The bearings were modeled as fixed in the transverse direction, and therefore the end condition of floor beam FB1 represented that of a fixed-ended beam. Away from the bearings, the torsional rigidity of the girder plays a significant role in the degree of end-fixity of the floor beams. The moment influence lines for the stringers indicate that sharp peaks should be expected in the simulated strain histories. However, it is anticipated that this model may actually overestimate measured stresses since significant longitudinal load distribution may occur due to the $0.254 \mathrm{~m}$ of ballast.

2.2. Refined Models. Two additional models (models 3 and 4) were created that simulate the effect of the track structure and ballast on the distribution of train loads. For models 3 and 4, the ballast, ties, and rails were added to models 1 and 2 (see Figure 6). Table 2 shows the section properties for the rails and ties which were modeled using frame elements.

The ballast was modeled using elastic springs with a stiffness calculated based on the ballast beneath the ties. The ballast under each of the rail ties was assumed to extend a distance of $h / 2$ in the longitudinal and transverse directions, where $h$ is the ballast depth (see Figure 7). Assuming linear elastic behavior, Hooke's Law was used to determine the spring constant, which amounted to $506 \mathrm{MN} / \mathrm{m}$. The elastic modulus for the ballast was taken as $137.9 \mathrm{MPa}$, which is

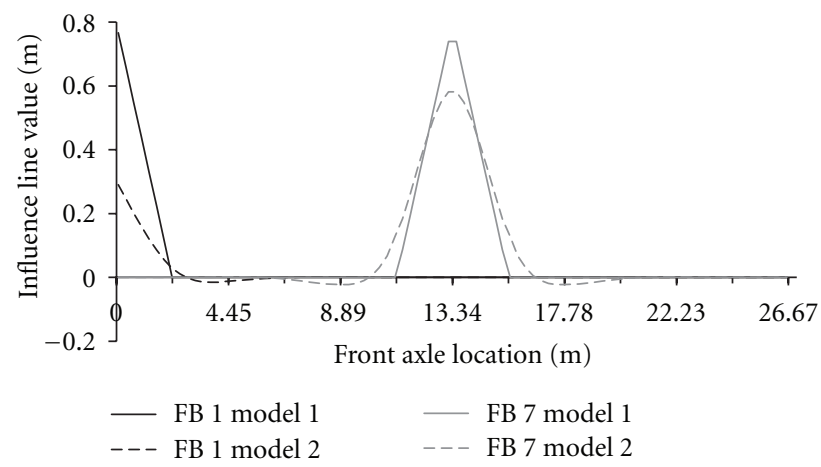

FIGURE 3: Moment influence lines for models 1 and 2 at midspan locations of floor beams FB1 and FB7.

approximately the average of the two values reported by Yang et al. [2] and Kuo and Huang [3] of $100 \mathrm{MPa}$ and $170 \mathrm{MPa}$, respectively. In the models, the four springs beneath the tie and above each of the stringers were assumed to work in parallel, and therefore $1 / 4$ of the total stiffness or $127 \mathrm{MPa} / \mathrm{m}$ was assigned to each spring element. Moment influence lines were created for Models 3 and 4 for comparison with models 1 and 2. Models 1 and 3 are compared in Figures 8 and 9 for the floor beams and stringers, respectively. It is important to note that similar to the connection fixity (see Figure 4), the ballast had essentially no effect on the girder response and therefore no results are shown. Since the girders are insensitive to both the fixity of the floor-system elements and the live-load spreading effect of the ballast, ties, and rails, measurements from the girders may be confidently used in a weigh-in-motion system since there are fewer parameters that affect these strain readings. As shown in Figure 8, the ballast slightly decreased the peak magnitude of the moment influence line of the interior floor beam, however, no change 


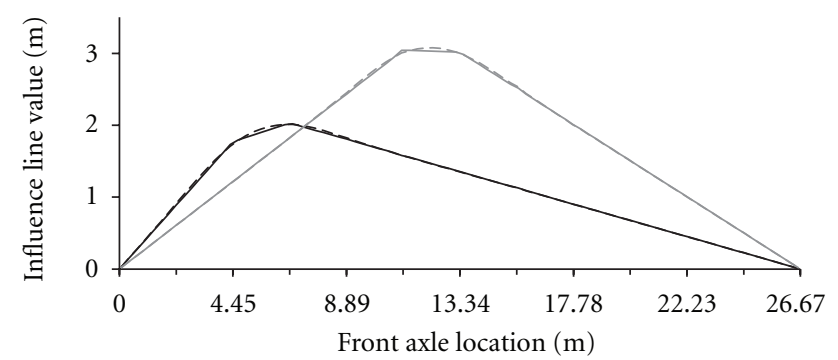

$\begin{array}{ll}- \text { G1 Qtr model 1 } & - \text { G7 Mid model 1 } \\ -- \text { G1 Qtr model 2 } & --- \text { G7 Mid model 2 }\end{array}$

Figure 4: Moment influence lines for models 1 and 2 at Bay B6 midspan location and quarter point of girder G1.

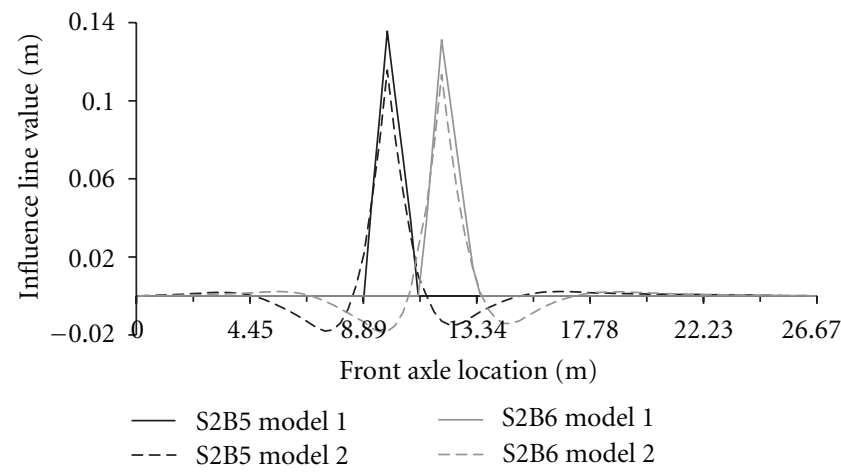

Figure 5: Moment influence lines for models 1 and 2 at Bays B5 and B6 midspan locations of stringer S2.

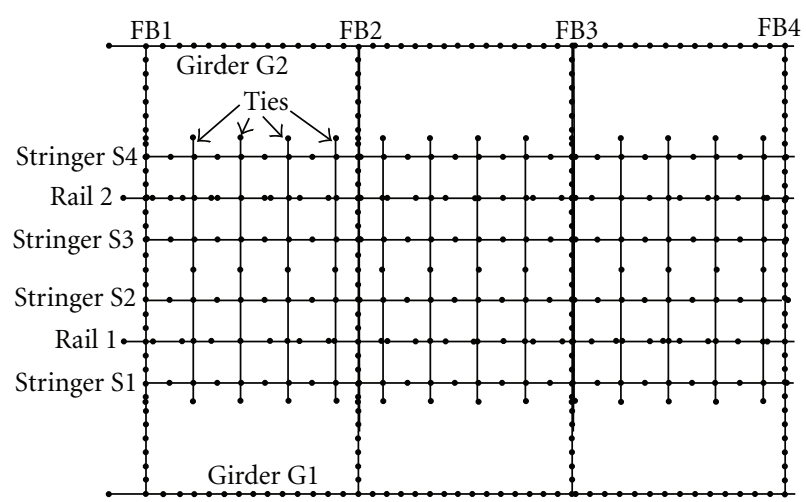

(a)

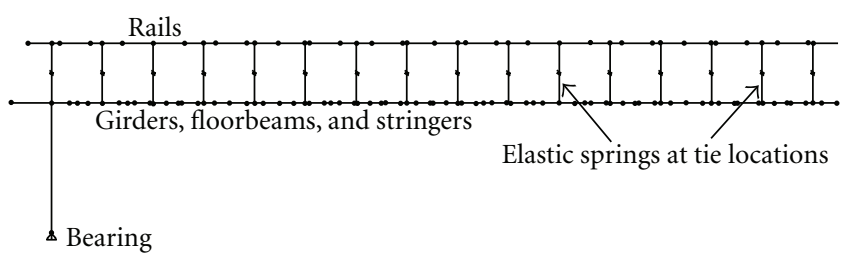

(b)

Figure 6: Models 3 and 4 of Bridge 880.37 near north support: (a) plan view and (b) profile view.

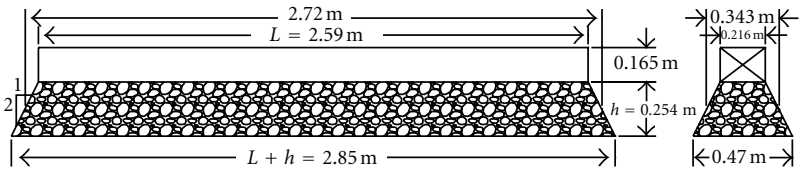

FIgURE 7: Ballast beneath ties used to determine spring constant.

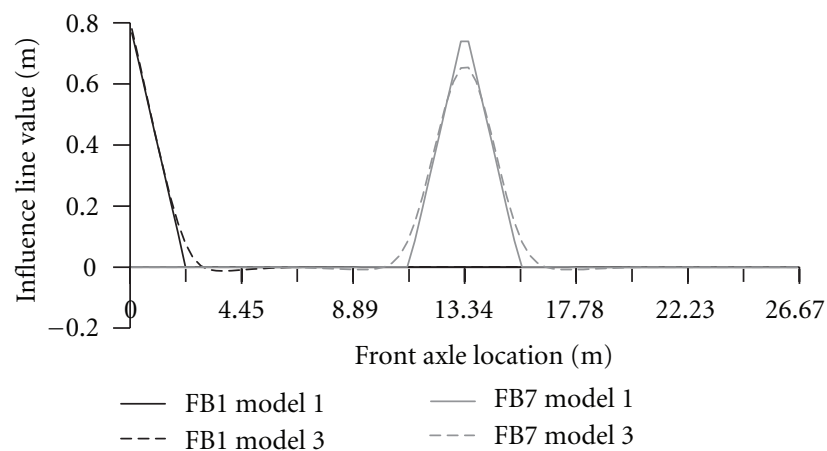

Figure 8: Moment influence lines for models 1 and 3 at midspan locations of floor beams FB1 and FB7.

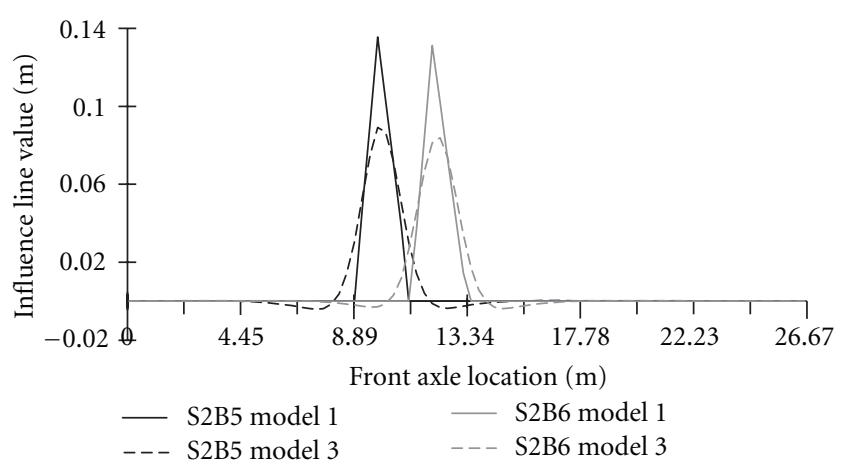

FIgure 9: Moment influence lines for models 1 and 3 at Bay B5 and B6 midspan locations of stringer S2.

occurred at the end floor beam. The stringers were affected significantly by the modeling of the ballast, track, and rails. This is evident by the large reductions in the peak moment influence line magnitudes shown in Figure 9. Note that compared to the basic model (model 1) where the response is the same for all four stringers, the reduction was greater for the exterior stringers for model 3. The larger response of the interior stringers can be explained by the fact that the ties in the lateral direction act as a continuous beam over four elastic supports. As such, the interior supports support a greater portion of the load when the load is equidistant from the exterior and interior stringer.

2.3. Generation of Influence Profiles. The moment influence lines previously developed were used to simulate strain histories for comparison to measured strains from diagnostic load tests. This was achieved using the following matrix operation: $[M]=[\mathrm{IL}] *[L]$, where $[M]$ is the moment history; [IL] is a row vector containing the moment influence 


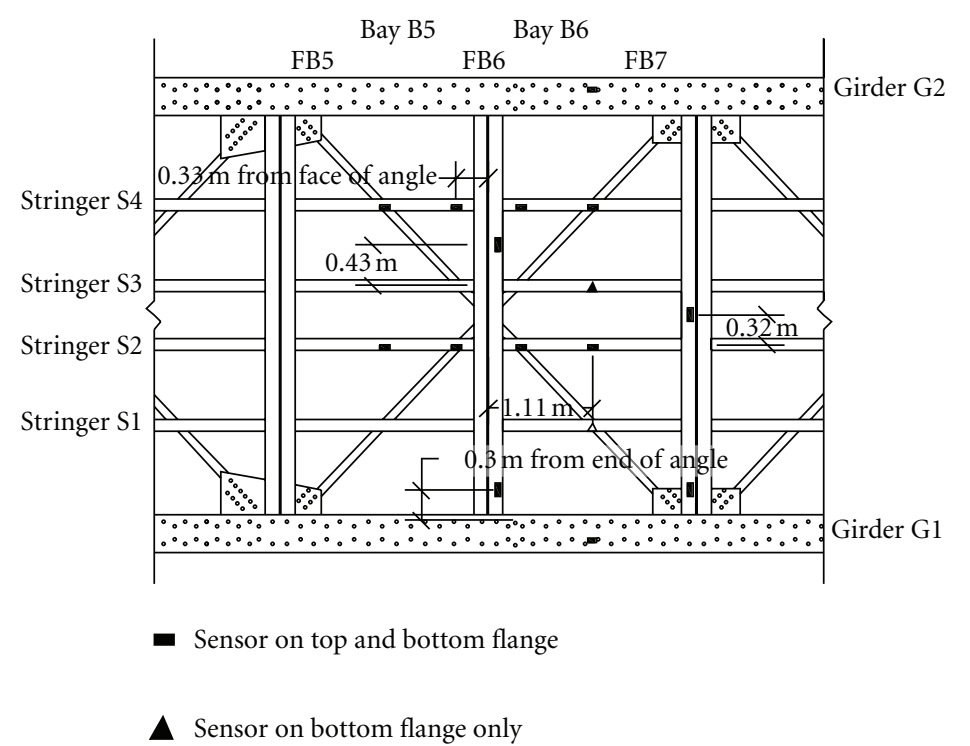

Figure 10: Sensor locations in Bays B5 and B6 of Bridge 880.37.

line ordinates; $[L]$ is a loading matrix that represents a moving train. The moment history can be easily converted to a strain history as follows: $[\varepsilon]=[M] /(S * E)$, where $[\varepsilon]$ is the strain history; $S$ is the section modulus for the member; $E$ is the elastic modulus for steel. The loading matrix must be developed carefully to ensure meaningful results. Each row of the $[L]$ matrix represents a longitudinal location which must correspond to each longitudinal location in the [IL] vector. Each column of the $[L]$ matrix represents one load step (i.e., the first column represents the train front axle directly above floor beam FB1, and the 7th column is $1.38 \mathrm{~m}$ past floor beam FB1 using a $0.305 \mathrm{~m}$ increment). To simplify the matrix, the longitudinal spacing for the moment influence line ordinates should equal the distance the train travels for each load case. Consequently, only the first row of the loading matrix (which represents the train configuration) requires user input. The matrix can be completed by entering a zero in the first column of each row beneath the first, and the remaining cells taken as the value of the cell above and to the left, thus, representing the movement of the train. Further details regarding this process are given in [12].

\section{Diagnostic Load Testing}

To better understand the load distribution and determine the best-fit model of Bridge 880.37, a diagnostic load test was performed. The sensors used in this study were strain "intelliducers" (which self-identify to the data acquisition system) from Bridge Diagnostics, Inc., (BDI), and the data acquisition system was the Structure Testing System (STS) II equipment and software [13]. The gauges were attached to the bridge by bolting steel tabs to the sensor, which were subsequently attached to the bare steel of the bridge using a strong epoxy adhesive.

3.1. Instrumentation Plan and Setup. The primary purpose of the load test was to capture the live-load distribution of the structure. Strain transducers were placed near the ends of selected stringers and floor beams to evaluate the level of end fixity of the riveted connections. To assess the longitudinal and transverse load distribution, sensors were placed on all four stringers and both girders near the center of the bridge. Figures 2 and 10 show the sensor locations. The gauges were placed on the bottom of the girders and stringers, the top of the bottom flange for the floor beams, and at the bottom of the top flange for all members where a top sensor is used.

3.2. Train Loading and Testing Procedure. The strain transducers were attached to the structure and connected to junction boxes which were routed to the data acquisition box and laptop computer. Using the BDI testing software, the system was initiated and the sampling rate was set at the maximum of $100 \mathrm{~Hz}$ since the trains were traveling at full speed (about $127 \mathrm{kph}$ ).

To reduce the effect of temperature and random drift of the sensors, the gauges were rezeroed between trains. Readings initiated on sight of the train and stopped once the last axle of the train exited the structure. A total of six load tests were completed under six different trains as described in Table 3. Axle weights and spacings were extracted from Dick [14] except those for the Rail Runner locomotive which were found on the manufacturer's website [15]. Table 4 and Figure 11 describe the train configurations applied in the load tests.

3.3. Processing of Strain Measurements. The raw strain data was first cropped and then corrected for drift and adjusted for a time lag that was observed in 20 of the sensors due to a recording delay between the channels of the data acquisition system. To crop the data, the measurements taken at floor beam FB1 were used to determine when the train had entered the structure for southbound trains or when the train had travelled the length of the bridge for northbound 
TABLE 3: Observed configurations of trains used in load tests.

\begin{tabular}{lcclc}
\hline Train Number & Train type & Time of crossing & Direction & Configuration \\
\hline 1 & Rail runner & $12: 30 \mathrm{PM}$ & Southbound & 1 engine; 3 passenger cars \\
2 & Amtrak & $3: 10 \mathrm{PM}$ & Southbound & 2 engines; 1 baggage car; 4 coach; \\
1 diner; 1 lounger; 3 sleepers \\
3 & Rail runner & $4: 45 \mathrm{PM}$ & Northbound & 3 passenger cars; 1 engine \\
4 & Rail runner & $5: 05 \mathrm{PM}$ & Southbound & 1 engine; 4 passenger cars \\
5 & Rail runner & $5: 59 \mathrm{PM}$ & Northbound & 2 passenger cars; 1 engine \\
6 & Rail runner & $6: 15 \mathrm{PM}$ & Southbound & 1 engine; 3 passenger cars \\
\hline
\end{tabular}

TABLE 4: Engine and rail car configurations.

\begin{tabular}{lcccc}
\hline & $\begin{array}{c}\text { Weight per axle } \\
\mathrm{kN}\end{array}$ & $\begin{array}{c}\text { LPFC* } \\
\mathrm{m}\end{array}$ & $\begin{array}{c}\mathrm{AS}^{*} \\
\mathrm{~m}\end{array}$ & $\begin{array}{c}\mathrm{TC}^{*} \\
\mathrm{~m}\end{array}$ \\
\hline Rail runner engine & 322 & 20.7 & 2.74 & 13.1 \\
Rail runner passenger car & 122 & 25.9 & 2.90 & 19.5 \\
Amtrak engine & 296 & 21.0 & 2.75 & 13.2 \\
Amtrak baggage car & 133 & 25.9 & 1.68 & 18.1 \\
Amtrak coach and lounger & 178 & 25.9 & 2.59 & 18.1 \\
Amtrak diner and sleeper & 189 & 25.9 & 2.59 & 18.1 \\
\hline
\end{tabular}

*Abbreviations defined in Figure 11.

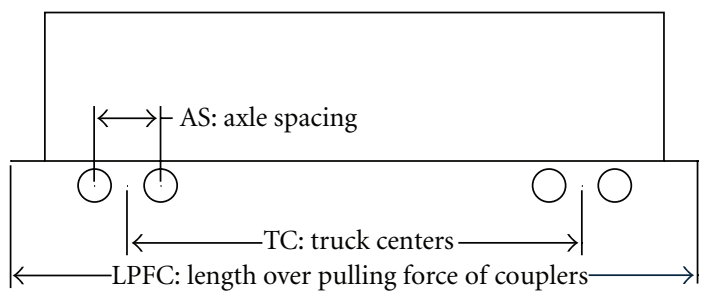

Figure 11: Definitions of abbreviations in Table 4.

trains. Sensor drift was then corrected using the following relationship:

$$
\varepsilon_{n^{\prime} . \text { adj }}=\varepsilon_{n^{\prime} \text {.measured }}-\varepsilon_{0}+\frac{n^{\prime}}{N^{\prime}} *\left(\varepsilon_{N^{\prime}}-\varepsilon_{0}\right),
$$

where $\varepsilon_{n^{\prime} \text {.adj }}$ is the adjusted strain reading; $\varepsilon_{n^{\prime} \text {.measured }}$ is the raw measured strain; $\varepsilon_{0}$ is the average strain before the train enters the structure; $n^{\prime}$ is the reading number; $N^{\prime}$ is the total number of readings between the train front axle entering and the last axle leaving the bridge; $\varepsilon_{N^{\prime}}$ is the average strain after the last axle leaves the structure.

As mentioned previously, a time lag was observed in 20 of the 36 sensors and at one location, the strain readings on the top and bottom flanges were offset. Since the time between the first peaks in the readings represented the time lag, the lagging data was simply shifted to the left. Figure 12 shows an example strain data set for a stringer before and after processing.

3.4. General Behavior Based on Measured Strains. The measured strains for each of the six trains at all 19 instrumented locations were processed as discussed in Section 3.3. In general, the shapes of the strain histories were as expected

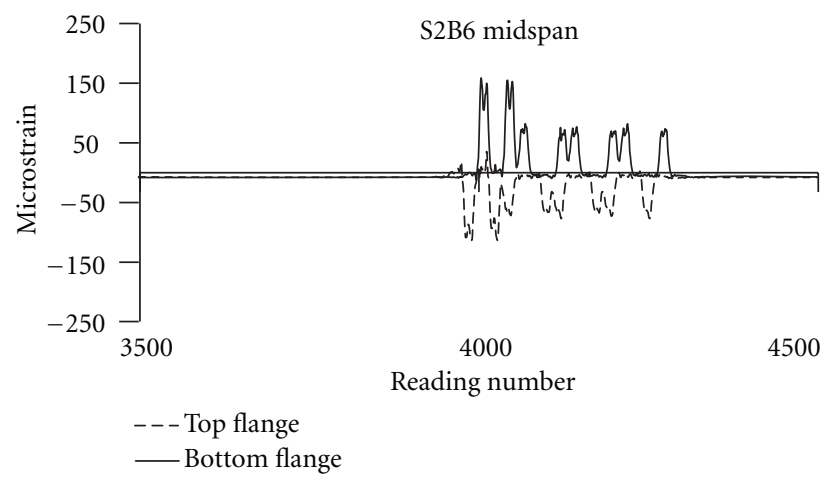

(a)

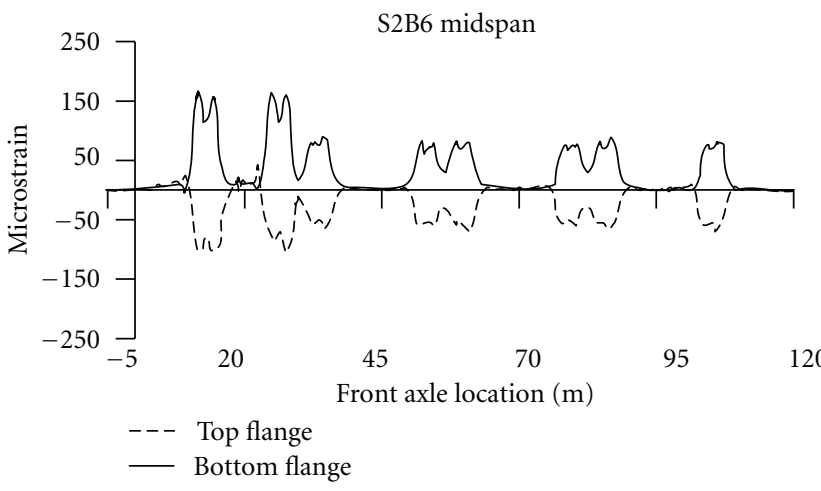

(b)

FIGURE 12: Typical response for stringer S2 at Bay B5 midspan: (a) raw strain data and (b) processed strain data corrected for drift, time lag, and axle location.

(e.g., a peak for each set of axles and peaks of similar magnitudes for each rail car). In Bay B6, the peak strain magnitudes were smallest in stringer S1 and largest in stringer S4, consistently increasing from west to east, as shown in Figure 13. This behavior was only observed under the locomotive, and possibly attributed to asymmetric weight distribution, or some dynamic effect of the diesel engine. Another observation was that tensile stresses developed in the stringers, particularly in Bay B5. At the instrumented ends of these stringers, pure tension was measured and at midspan, the tension flange strains were significantly larger than the compression flange strains. Similar behavior was observed in Bay B6, but to a smaller extent. This can be 


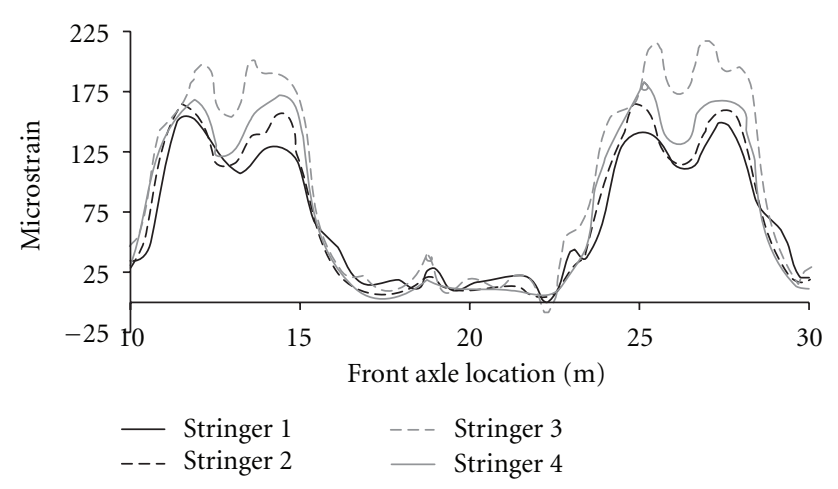

FIGURE 13: Illustration of asymmetric live-load distribution under the locomotive for Train 1.

TABle 5: Neutral axis positions determined from drawings and strain measurements.

\begin{tabular}{lccc}
\hline & From drawings & From strain data & Difference (\%) \\
\hline & $\mathrm{cm}$ & $\mathrm{cm}$ & $\%$ \\
\hline Floorbeams & 30.5 & 31.2 & $2.9 \%$ \\
Girder X5 & 132 & 123 & $-6.3 \%$ \\
Girder X6 & 133 & 131 & $-2.0 \%$ \\
Stringers & 15.2 & 18.5 & $21.5 \%$ \\
\hline
\end{tabular}

Note: Neutral axis locations taken from bottom of member.

explained by the fact that the stringers behave in conjunction with the girders and resist some of the tensile flexural stresses that would otherwise be resisted by the girder bottom flanges.

Assuming linear strain distribution, the neutral axis positions were estimated at all locations where strains were measured at the top and bottom flanges. The average measured neutral axis positions are given in Table 5 compared to those calculated from the as-built plans. For the girders and floor beams, the average neutral axis locations based on strain measurements were close to the values obtained from the drawings. For the stringers, the average neutral axis location based on measured strains was significantly higher, which can be explained by the behavior discussed earlier, and partial composite action with the deck. It was also observed that minimal negative flexure developed at the ends of the stringers and floor beams with two exceptions: the stringers in Bay B5 and floor beam FB1. This may indicate negative flexure, since the instrumented location may have been near the points of inflection.

\section{Evaluation of Best-Fit Model}

The finite-element models were evaluated by comparing the shapes of the simulated and measured strain profiles, and also the peak strains from each passing train. It was found that the actual train speeds varied from $125 \mathrm{kph}$ to $126 \mathrm{kph}$. The models were further evaluated based on PalmgrenMiner's sum for future use in a fatigue evaluation.

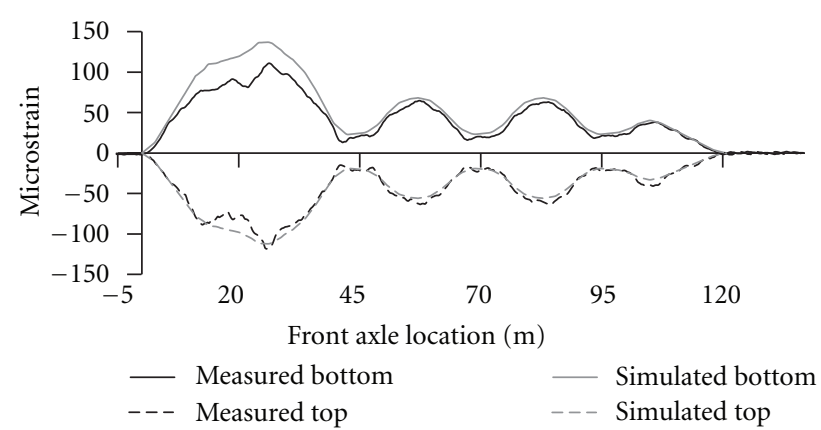

(a)

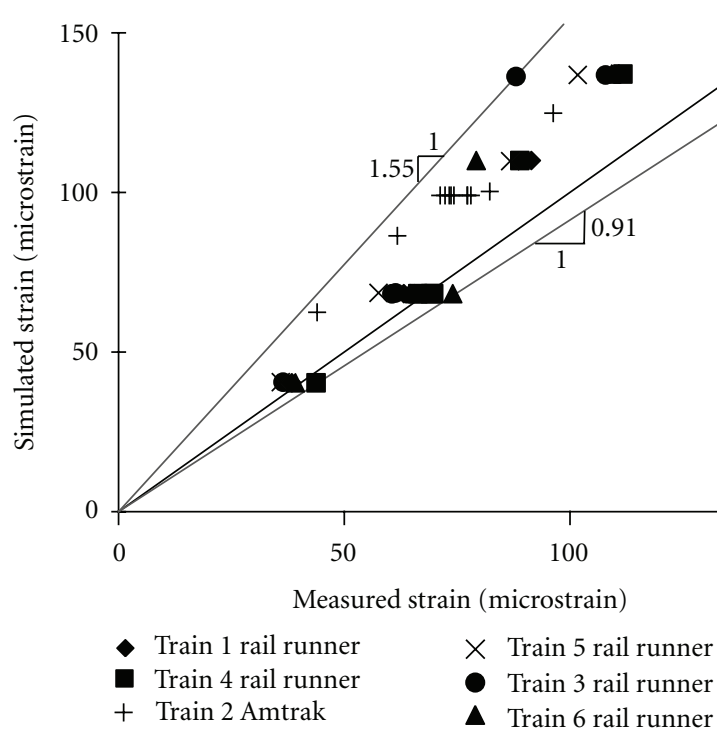

(b)

Figure 14: Simulated (Model 1) versus measured response near midspan of girder G2: (a) strain profiles for Train 1 and (b) peak strains for all trains.

4.1. Measured versus Simulated Girder Strains. Figure 14 shows the simulated versus measured strains near midspan of Girder G2 for model 1 since all four models behaved nearly the same. As shown in Figure 14(a), the strains match very well under Train 1, particularly for the rail cars, which are represented by the three smaller peaks in the data. For all the trains, it is also apparent that the locomotive weights may have been overestimated since the simulated strains consistently exceeded the measured strains under the locomotives as shown in Figure 14(b) (locomotive strains are represented by the first peak in the strain data). For the Rail Runner trains, the peak strain correlation was very close to the $1: 1$ line for the passenger cars, but as much as 1.5:1 for the locomotives. For the Amtrak train, both the locomotive and passenger cars showed higher simulated strains compared to the measured strains. The difference between the measured and simulated strains may be attributed to differences in the actual weights of the rail equipment when compared to the estimated weights taken from the manufacturer, which were used when developing the simulated strain histories. 


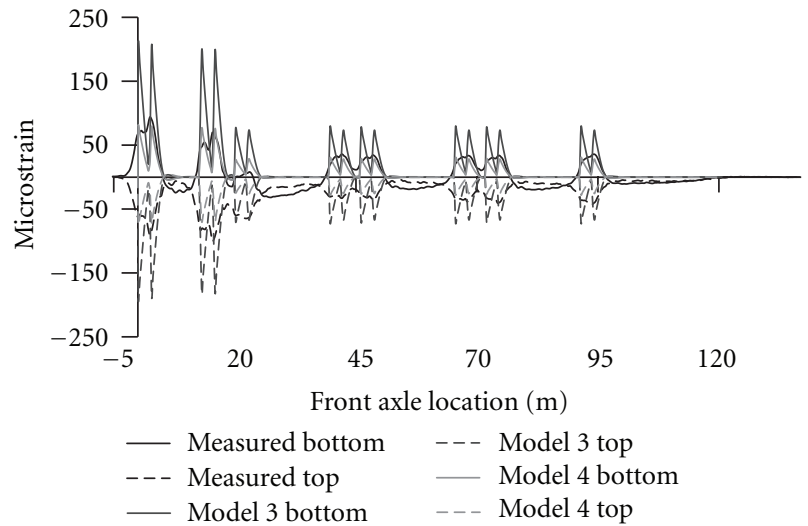

(a)

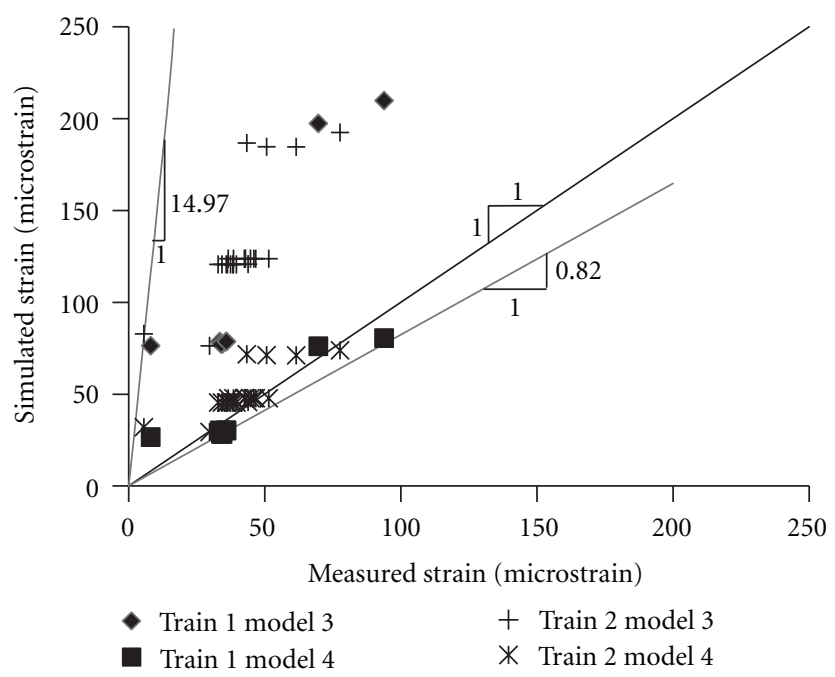

(b)

FIGURE 15: Simulated versus measured response at midspan of floor beam FB1: (a) strain profiles for Train 1 and (b) peak strains for Trains 1 and 2.

4.2. Measured versus Simulated Floor Beam Strains. Similar comparisons were made for the floor beams however, unlike the girders there were differences between the models. For the end floor beam FB1, the simulated response was significantly affected by the end fixity. As shown in Figure 15, the pinned connection model (i.e., model 3) significantly overestimated the measured strains whereas the fixed connection model (i.e., model 4) resulted in a very close agreement of peak strains, although the model does yield some results below the $1: 1$ line.

For the interior floor beams (FB6 and FB7), it was found that the influence of the end-fixity and ballast was minimal. The pronounced effect of the end-fixity on the end floor beam compared to the interior floor beams can be attributed to the bearings and torsional rigidity of the girders as mentioned earlier. None of the floor beams were affected significantly by the modeling of the ballast, ties, and rails. This is logical since, assuming the load is spread over a relatively small distance, the difference in the distribution to the floor beams is small. The results from this section

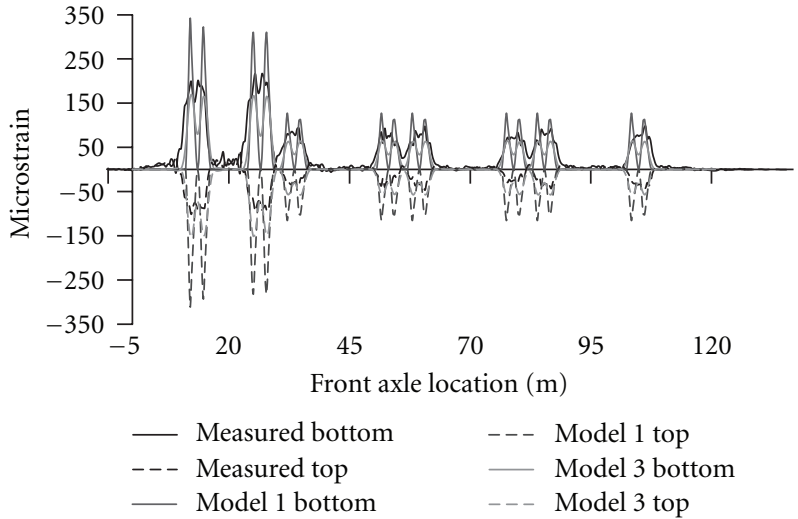

(a)

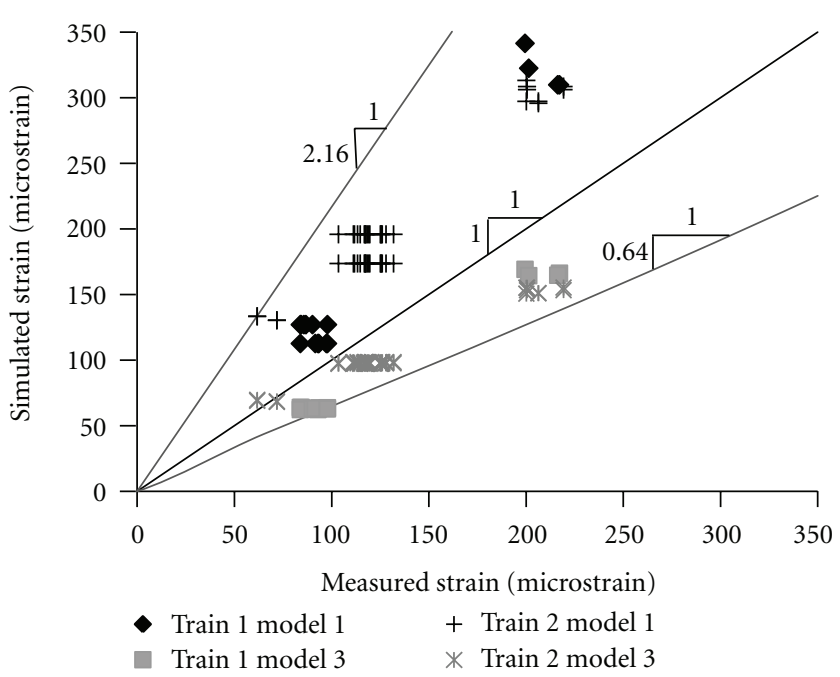

(b)

FIGURE 16: Simulated versus measured response at midspan of Stringer S4 in Bay B6: a) strain profiles for Train 1 and b) peak strains for Trains 1 and 2 .

show potential in guiding a bridge inspector to locations that are more likely to experience fatigue related failure since it was shown that the end floor beam may develop negative moments at the ends, thus, causing stresses that were not likely considered in design.

4.3. Measured versus Simulated Stringer Strains. The strain comparisons are given in Figure 16 for Stringer S4 at the midspan of Bay B6. This location was chosen since the maximum measured stringer response occurred here. models 1 and 3 were compared since the stringers were more sensitive to load spreading through the ballast than endfixity. Models 2 and 4 resulted in lower strains than models 1 and 3, respectively. The shapes of the curves also match much better when the pinned-end models are used. Based on the strain profile comparisons, model 3 appears to more accurately capture the shape of the measured strains and the peak magnitudes, although the results fell below the 1:1 line. For this model, the simulated strains for the interior stringers were greater than those for the exterior stringers. If the 
TABle 6: Palmgren-Miner's sums based on measured and simulated strains.

\begin{tabular}{|c|c|c|c|c|c|c|c|c|c|}
\hline & \multicolumn{5}{|c|}{ Miner's sums } & \multicolumn{4}{|c|}{ Difference from measured (\%) } \\
\hline & $\begin{array}{c}\text { Measured } \\
\left(* 10^{-9}\right)\end{array}$ & $\begin{array}{l}\text { Model } 1 \\
\left(* 10^{-9}\right) \\
\end{array}$ & $\begin{array}{l}\text { Model } 2 \\
\left(* 10^{-9}\right) \\
\end{array}$ & $\begin{array}{l}\text { Model } 3 \\
\left(* 10^{-9}\right) \\
\end{array}$ & $\begin{array}{l}\text { Model } 4 \\
\left(* 10^{-9}\right) \\
\end{array}$ & Model 1 & Model 2 & Model 3 & Model 4 \\
\hline \multicolumn{10}{|l|}{ Train 1} \\
\hline G1B3 midspan & 1.27 & 2.26 & 2.32 & 2.26 & 2.31 & $78 \%$ & $83 \%$ & $78 \%$ & $82 \%$ \\
\hline G2B6 midspan & 2.48 & 4.10 & 4.19 & 4.11 & 4.18 & $65 \%$ & $69 \%$ & $66 \%$ & $68 \%$ \\
\hline FB1 midspan & 4.14 & 53.7 & 2.7 & 51.0 & 2.96 & $1196 \%$ & $-34 \%$ & $1131 \%$ & $-29 \%$ \\
\hline FB7 midspan & 5.38 & 26.2 & 24 & 22.6 & 26.1 & $387 \%$ & $348 \%$ & $319 \%$ & $385 \%$ \\
\hline S2B6 midspan & 1.30 & 17.0 & 8.51 & 3.11 & 1.99 & $1205 \%$ & $555 \%$ & $139 \%$ & $53 \%$ \\
\hline S4B6 midspan & 2.72 & 17.0 & 7.93 & 1.43 & 0.85 & $524 \%$ & $192 \%$ & $-47 \%$ & $-69 \%$ \\
\hline \multicolumn{10}{|l|}{ Train 2} \\
\hline G1B3 midspan & 2.47 & 4.62 & 4.58 & 4.52 & 4.55 & $87 \%$ & $86 \%$ & $83 \%$ & $84 \%$ \\
\hline G2B6 midspan & 4.09 & 7.95 & 7.92 & 7.81 & 7.90 & $94 \%$ & $94 \%$ & $91 \%$ & $93 \%$ \\
\hline FB1 midspan & 10.4 & 152 & 8.1 & 150 & 8.86 & $1369 \%$ & $-22 \%$ & $1349 \%$ & $-15 \%$ \\
\hline FB7 midspan & 12.3 & 80.1 & 66 & 64.2 & 67.6 & $551 \%$ & $434 \%$ & $422 \%$ & $450 \%$ \\
\hline S2B6 midspan & 3.87 & 50.8 & 29.9 & 9.51 & 7.32 & $1211 \%$ & $674 \%$ & $146 \%$ & $89 \%$ \\
\hline S4B6 midspan & 7.68 & 50.8 & 27.1 & 4.36 & 3.13 & $560 \%$ & $253 \%$ & $-43 \%$ & $-59 \%$ \\
\hline
\end{tabular}

${ }^{*}$ G1B3 indicates girder G1 in Bay B3; G2B6 indicates girder G2 in Bay B6; S2B6 and S4B6 indicate stringers S2 and S4, respectively, in Bay B6.

maximum stringer response from model 3 (i.e., the response for an interior stringer) is compared to the measured strains at stringers S4, bay B6 midspan (as shown in Figure 16), the simulated strains more closely approximate the measured strains, and the slope of the lower-bound line is 0.81 rather than 0.64 .

Modeling the stringers requires greater care than the modeling of the girders and floor beams since the stringers are sensitive to both the end-fixity and to the modeling of the ballast, ties, and rail. Correctly modeling the end-fixity is also more difficult for the stringers than for the floor beams since the level of fixity is affected by the rigidity of the double angle connections and the out-of-plane rigidity of the floor beam web. The potential contribution of the stringers in tension and the possibility for partial composite behavior with the deck also must be considered. Considering the many factors affecting the behavior of the stringers, the results from the finite-element models described the measured behavior quite well.

4.4. Comparisons Based on Palmgren-Miner's Sums. Apart from the comparisons of strain histories and peak strains, the Palmgren-Miner's sums were determined to further evaluate the models. For Bridge 880.37, the critical fatigue details for the girders and floor beams are classified as category D based on the AREMA specifications [6] and category A for the stringers away from the connections. To obtain the Palmgren-Miner's sums, the strain histories were first converted to stress histories (by multiplying by the modulus of elasticity) which were then processed using a rainflow counting algorithm [16] developed in MATLAB [17] to determine the stress range magnitudes and corresponding number of stress cycles. Subsequently, the
Palmgren-Miner's sums were determined using the following equation:

$$
D=\sum_{1}^{k} \frac{n_{i}}{N_{i}}=\sum_{1}^{k} \frac{n_{i}}{n_{o}} *\left(\frac{\Delta \sigma_{i}}{\Delta \sigma_{o}}\right)^{3}
$$

where $D$ is the Palmgren-Miner's sum; $n_{i}$ is the number of stress cycles at the ith stress range magnitude; $\Delta \sigma_{i}$ is the ith stress range magnitude; $n_{o}$ is the number of cycles at the knee point of the SN curve; $\Delta \sigma_{o}$ is the stress range at the knee point; $k$ is the number of different stress cycles. For the riveted details, $n_{o}$ is 6 million cycles and $\Delta \sigma_{o}$ is $48.2 \mathrm{MPa}$ as specified in AREMA [6] and for the stringers away from the connections, $n_{o}$ is 2 million cycles and $\Delta \sigma_{o}$ is $165 \mathrm{MPa}$.

The Palmgren-Miner's sums based on the measured and simulated strains vary widely between models and between different locations for the same model (see Table 6).

Results are only shown for Trains 1 and 2; however, the trends and percentage of differences are consistent from train to train. The percentage of difference indicates the percentage of difference between the measured and simulated PalmgrenMiner's sum for a particular location. The pinned connection models (i.e., models 1 and 3) have higher Palmgren-Miner's sums than the fixed connection models (i.e., models 2 and 4) for the stringers and end floor beam locations. Models 3 and 4 have lower Palmgren-Miner's sums than Models 1 and 2 for the stringers because of the load spreading effect. Floor beam FB1 appears to be the least accurately depicted by the pinned connection models. At this floor beam, the PalmgrenMiner's Sum based on measured strains was much smaller. In addition, the Palmgren-Miner's sums based on simulated strains for floor beam FB1 were double the corresponding values for an interior floor beam. This behavior is mainly 
attributed to the larger degree of end-fixity developed at the end floor beam compared to the interior floor beams as discussed earlier. Thus, the fixed connection models match the measured data the best for the end floor beam.

At S4B6 midspan, model 3 underestimated the Palmgren-Miner's sum based on measured strains; however, if this model was used in an engineering analysis, the most critical stringer would be used, since the member with the highest stress ranges would be the critical member in the analysis. The critical stringer location using model 3 is S2B6 midspan and S4B6 midspan for the measured strains. If these Palmgren-Miner's sums are compared then model 3 is conservative by $14 \%$ for Train 1 and $24 \%$ for Train 2, which would yield very good results in a fatigue evaluation. The Palmgren-Miner's sums for the girders and interior floor beam were very similar from model to model, signifying insensitivity to the end-fixity of the floor-system members and the ballast modeling, and model 3 appeared to be the closest to the measured values. The models overestimated the Palmgren-Miner's sum by $65 \%$ to $94 \%$ for Girders G1 and G2, and by $319 \%$ to $551 \%$ for Floor beam FB7. More accurate locomotive weights would likely lead to greater convergence between the simulated and measured behavior.

\section{Conclusions and Future Work}

Based on the four models, it was found that those which consider the ballast, ties and rails perform better than the simpler models. For the girders and interior floor beams, the difference in response for the four models was small since these members were insensitive to the end-fixity of the floor-system members and to the modeling of the ballast, but model 3 was found to give the best results. This insensitivity to the parameters mentioned indicates that measurements taken at the girders may be useful in a weigh-in-motion system since only the axle weights will likely affect the measurements significantly. For the end floor beam, model 4 was closest to the actual response and model 2 also gave reasonably accurate results. There was a significant difference between the pinned and fixed ended models for the end floor beam due to the stiffness of the bearing in the transverse direction. Based on these results for the girders and floor beams, the level of analysis had a small impact on the accuracy of the simulated responses. Therefore, a relatively simple model is sufficient if only the girders and floor beams require evaluation; however, a slight improvement is achieved when the ballast, ties, and rails are included in the model.

The stringers were sensitive to both the end-fixity and the modeling of the ballast. It was found that if the critical stringer is evaluated, model 3 provides the most accurate results, particularly if a Palmgren-Miner's sum is desired for a fatigue evaluation. Although the stringers require a more complex model, it may not be required in many cases when evaluating fatigue. Based on the results of this study, the endfixity of the stringers is minimal, and, therefore, the stress ranges at the ends are likely to be small, thus, the midspan of the member is critical for fatigue. Since the stringers are rolled steel shapes, they are relatively unsusceptible to fatigue failure, and as such an analysis utilizing a simple, yet significantly conservative model may be sufficient to indicate that the stringers are unlikely to pose a fatigue-related risk. For the end floor beam, in spite of being closer to the actual response, the simulated values were at times underestimated. This can be remedied by applying a factor that accounts for the modeling error. Furthermore, if this model was used in a fatigue evaluation using the AREMA [6] specifications, factors would also be applied to account for vertical impact and rocking effects.

Work based on this study, including a fatigue evaluation of Bridge 880.37 to estimate the remaining fatigue life is published elsewhere [18]. To achieve this, representative trains were developed for various eras dating back to the construction of the bridge, which were used along with the known current train traffic. These loads were then applied to the most accurate models, as determined in this paper. The matrix multiplication discussed in Section 2.3 can be rearranged to obtain the moment influence line for a specific location based on strain measurements. These influence lines can then be used to observe changes in the live load distribution of the bridge that may indicate structural damage. The moment influence lines can also be used in lieu of analytical models for evaluating the bridge under historical loading [18].

\section{References}

[1] M. Al-Emrani and R. Kliger, "FE analysis of stringer-tofloor-beam connections in riveted railway bridges," Journal of Constructional Steel Research, vol. 59, no. 7, pp. 803-818, 2003.

[2] L. A. Yang, W. Powrie, and J. A. Priest, "Dynamic stress analysis of a ballasted railway track bed during train passage," Journal of Geotechnical and Geoenvironmental Engineering, vol. 135, no. 5, pp. 680-689, 2009.

[3] C. M. Kuo and C. H. Huang, "Two approaches of finite-element modeling of ballasted railway track," Journal of Geotechnical and Geoenvironmental Engineering, vol. 135, no. 3, pp. 455-458, 2009.

[4] P. C. Paris, M. P. Gomez, and M. E. Anderson, "A rational analytical theory of Fatigue," Trends in Engineering, vol. 13, pp. 9-14, 1961.

[5] AASHTO, LRFD Bridge Design Specifications, American Association of State Highway and Transportation Officials, Washington, DC, USA, 5th edition, 2010.

[6] AREMA, Manual for Railway Engineering, American Railway Engineering and Maintenance-of-Way Association, Lanham, Md, USA, 2007.

[7] A. Palmgren, "Die Lebensdauer von Kugellagern. (The life of roller bearings)," Zeitschrift des Vereines Deutscher Ingenieure, vol. 68, no. 14, pp. 339-341, 1924 (German).

[8] M. A. Miner, "Cumulative damage in fatigue," ASME Journal of Applied Mechanics, vol. 12, no. 3, pp. A159-A1964, 1945.

[9] H. Agerskov, "Fatigue in steel structures under random loading," Journal of Constructional Steel Research, vol. 53, no. 3, pp. 283-305, 2000.

[10] Federal Register, "Bridge safety standards," vol. 75, no. 135, 2010.

[11] SAP2000 Version 14.2.2, Computers and Structures, Berkely, Calif, USA, 2010. 
[12] A. Daumueller and D. Jauregui, "Development of a structural health monitoring system for the assessment of critical transportation infrastructure," Tech. Rep. Sand2012-0886, Sandia National Laboratories, Department of Energy, February 2012.

[13] BDI, Structural Testing System II Operation Manual, Bridge Diagnostics, Boulder, Colo, USA, 2005.

[14] S. M. Dick, Bending moment approximation for use in fatigue life evaluation of steel railway girder bridges [Ph.D. thesis], Department of Civil, Environmental and Architectural Engineering, University of Kansas, Lawrence, Kan, USA, 2002.

[15] MotivePower, "MPX Commuter Locomotive," Locomotives, 2010, http://www.motivepower-wabtec.com/locomotives/commuter/mpxpress.php.

[16] A. Niesłony, "Determination of fragments of multiaxial service loading strongly influencing the fatigue of machine components," Mechanical Systems and Signal Processing, vol. 23, no. 8, pp. 2712-2721, 2009.

[17] MATLAB R2010b, The MathWorks, Natick, Mass, USA, 2010.

[18] A. Daumueller, Strain-based evaluation of a riveted steel railroad bridge [Ph.D. dissertation], New Mexico State University, Las Cruces, NM, USA, 2012. 

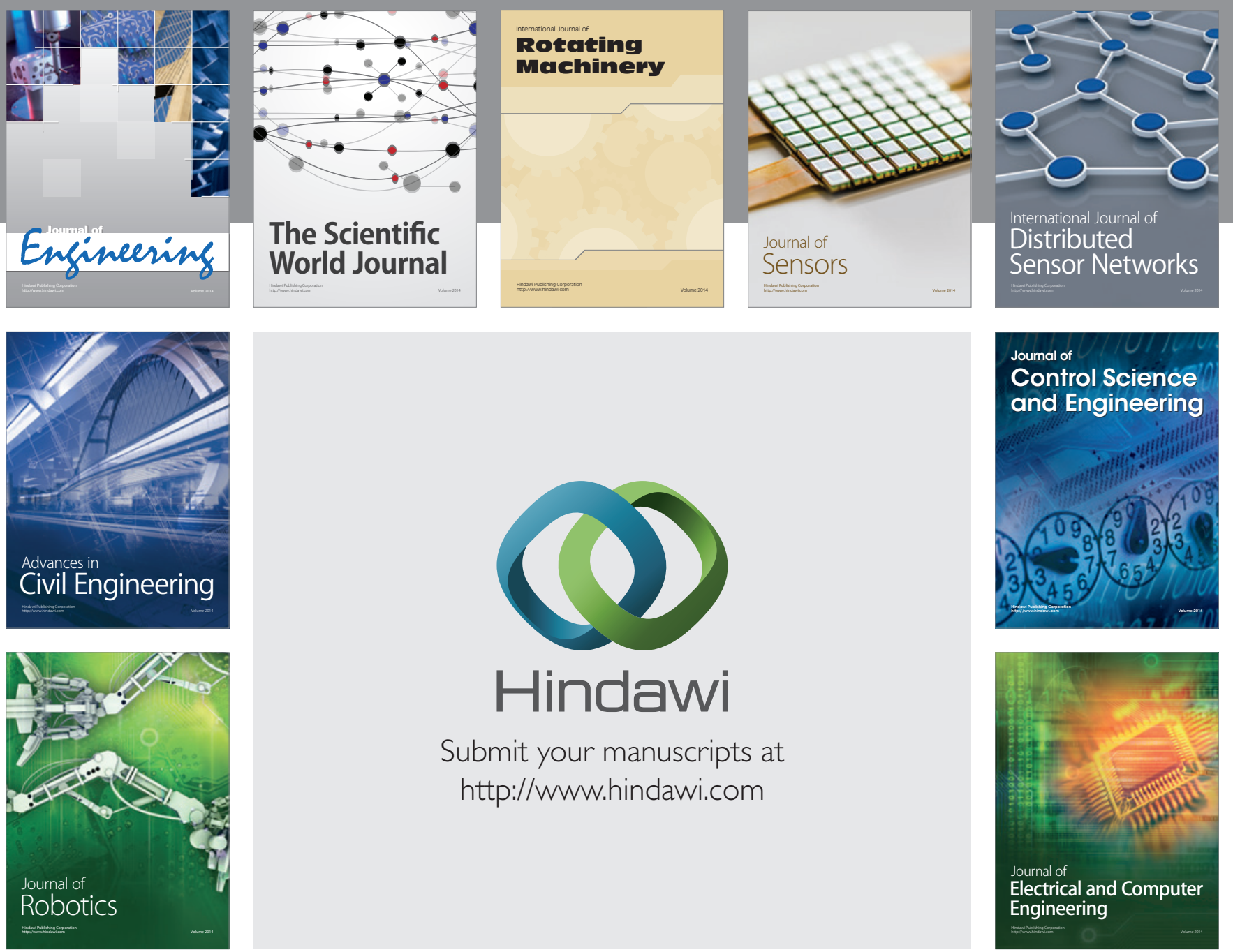

Submit your manuscripts at

http://www.hindawi.com
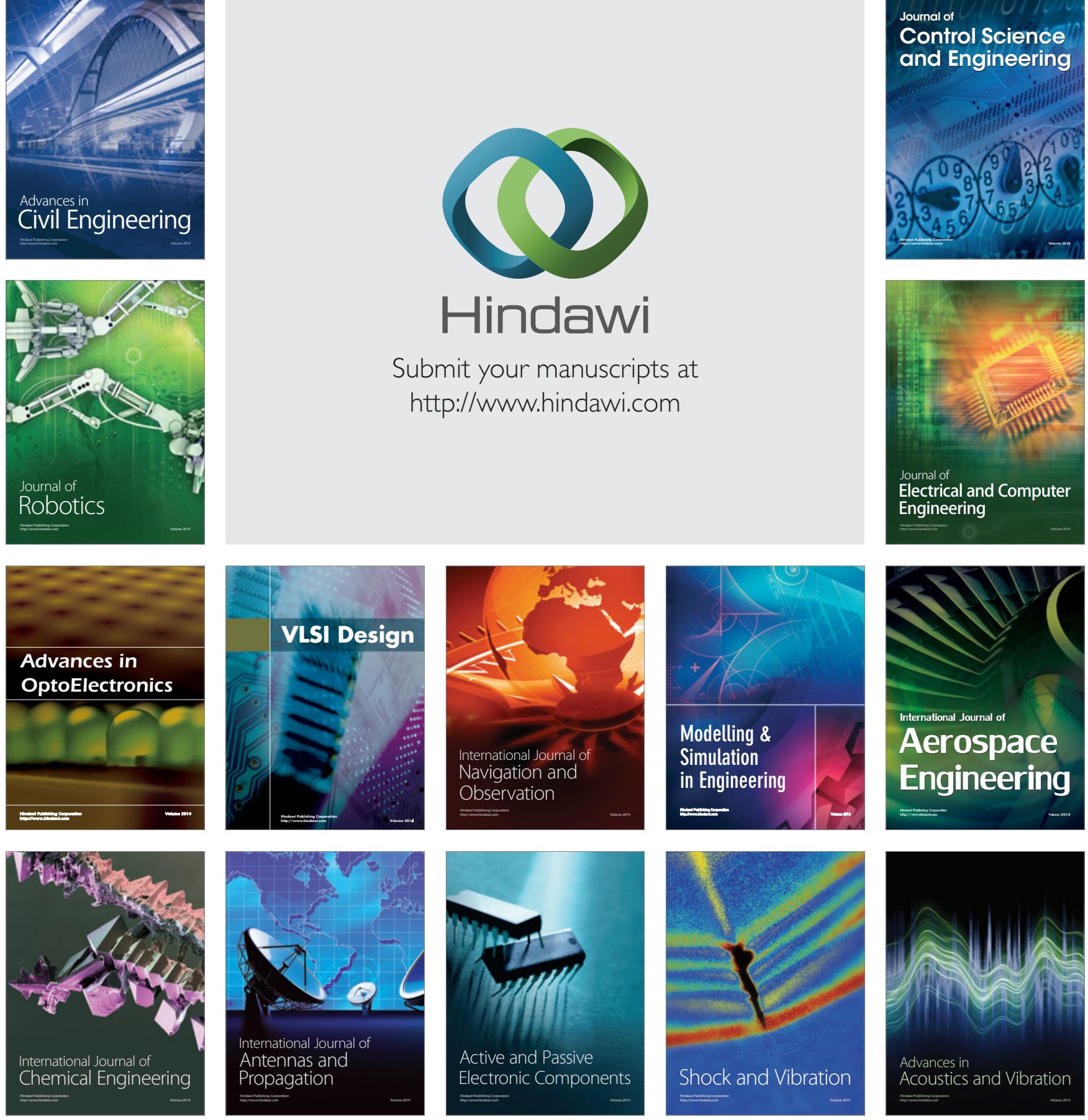